\title{
A REVIEW: THE EFFECT OF OPERATING CONDITIONS AND THERMAL MANAGEMENT ON THE PERFORMANCES OF METAL HYDRIDE HYDROGEN STORAGE TANKS
}

\author{
Taurista Perdana Syawitri \\ Department of Mechanical Engineering, Universitas Muhammadiyah Surakarta \\ Jl. A. Yani Tromol Pos 1 Pabelan, Kartasura, Surakarta 57102, Indonesia \\ Email:tps123@ums.ac.id
}

\begin{abstract}
For safety and operability concerns, the use of metal hydrides to store hydrogen appears to be particularly promising option for alternative energy at present. However, the process of adding, removing and distributing heat during the hydrogen charging/ discharging process is problematic due to the poor effective thermal conductivity of the metal hydride porous bed and the high enthalpies of $\mathrm{H}_{2}$ adsorption/desorption. Therefore, heat transfer is a critical factor affecting the performance of metal hydride hydrogen (MHR) storage tanks. Over decade, many researches focused on MHR's operating conditions and its thermal management to improve its performance.
\end{abstract}

\section{INTRODUCTION}

Nowdays, there are a lot of concerns over the decreasing of fossil energy sources in the world and the greenhouse gas emissions effects. These concerns have triggered the search for alternative and cleaner energy sources [1]. Among the various alternatives available, hydrogen fuel has attracted particular attention due to its high caloric value, zero environmental impact, and uncomplicated of production from various renewable energy sources $[2,3]$. However, how to store hydrogen is still remain as a challenge.

Hydrogen can be stored as compressed gas in high pressure tanks, as liquid in cryogenic tanks, or as absorbed element by solid materials in porous tank [4]. The gas compression method needs extremely high storage pressures (see Figure 1.1 [5]). The high compression pressure may cause safety risks and much energy consumption for charging hydrogen. The volumetric energy density of the liquid storage method is also inconvenient for automotive applications and needs high cooling energy because of its low storage temperature. The adsorption and desorption of hydrogen by solid materials, such as metal hydrides, have sufficiently high volumetric energy density and marginal safety risk because it requires relatively low charging pressure [6]. Accordingly, metal hydrides appear as a promising candidate for hydrogen storage medium.

The process of hydrogen storage in metal hydrides is associated with heat release during hydrogen adsorption and heat consumption during desorption. The processes of adding, removing and distributing heat during the hydrogen charging/discharging process are challenging due to the poor effective thermal conductivity of the metal hydride porous bed and the high enthalpies of $\mathrm{H}_{2}$ adsorption/desorption [3]. Moreover, with the fast development of fuel cell based hydrogen energy as a fuel technology in the last two decades, developing effective metal hydride storage devices is needed. Rather than the energy density and cost concerns, the hydrogen charging and discharging processes must be sufficiently fast to satisfy the short refueling time and dynamic load change. Therefore, understanding the heat and 
mass transfer and the hydrogen adsorption and desorption processes is critically important.

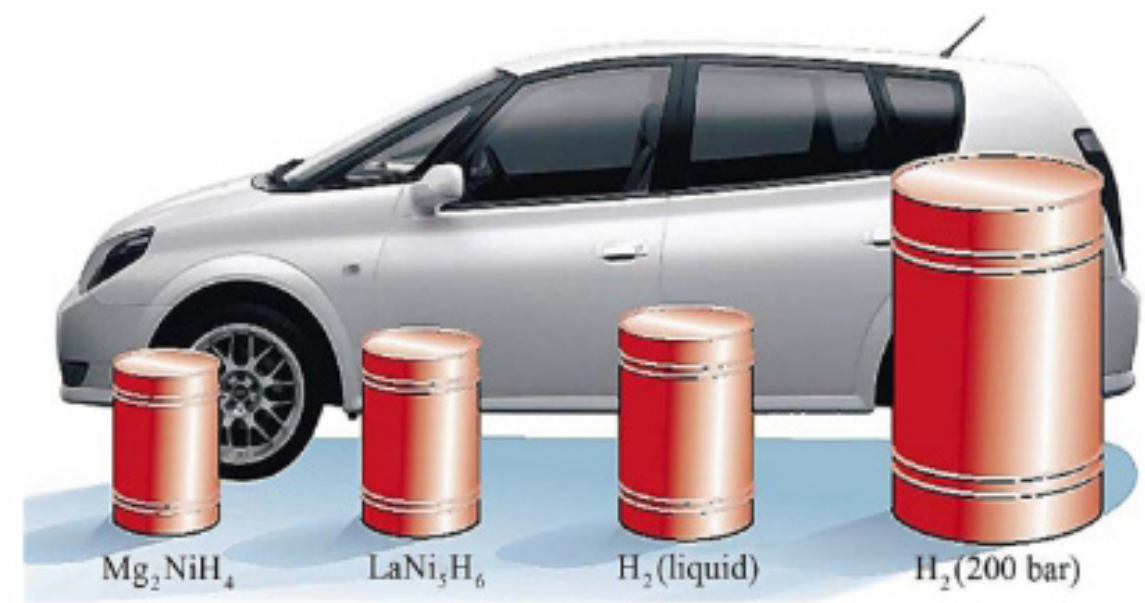

Figure 1.1 Volume of $4 \mathrm{~kg}$ of hydrogen compacted in different ways, with size relative to size of a car (Image of car of Toyota press information, 33rd Tokyo Motor Show, 1999 [5].).

It was shown by many researchers that the performance of a metal hydride reactor (MHR) is strongly affected by the operating conditions (such as the heat transfer fluid temperature and reactor inlet/exit pressure $[1,6,7]$ and thermal management (such as heat conduction augmentation $[8,9,10])$ of the system. This paper reviewed about some researches about these two problems.

\section{RESEARCHES ABOUT THE EFFECTS OF OPERATING CONDITIONS}

In this sub section, some studies about the investigation of the effect of various operating conditions to the performance of MHR are explained.

Maad et al [1] simulated 2-D axisymmetric MHR containing metal hydride $\mathrm{Mg}_{2} \mathrm{Ni}-\mathrm{H}_{2}$. In this study, the radiative heat transfer was taken into account. This study found that the right choice of the external heating fluid and the outlet pressure was strongly necessary to optimize the reactor operation. It was also found that radiative heat transfer had an important effect on the discharge process of the reactor and heat and mass transfer was very sensitive to the coefficient of heat transfer, $h$, between the hydride and the external environment. However, beyond a certain value (in this case for $h$ is higher than $100 \mathrm{~W} / \mathrm{m}^{2} \mathrm{~K}$ ) this effect became negligible.

Investigation about the effect of various operating conditions to the performance of MHR was also conducted by Jiao et al. [6]. This study simulated a 2-D axisymmetric cylindrical $\mathrm{LaNi}_{5}$ metal hydride tank under various cooling levels, charging pressures and environmental temperatures. This study focused on the analysis of the effect of those three operating conditions on the performance, transport phenomena and hydrogen absorption/ desorption processes. The numerical results showed that the fastest charging process occurred within the first $20 \mathrm{~s}$, and the fastest charging rate and duration were mainly affected by the charging pressure and initial temperature, respectively. The effect of cooling level on this process was insignificant.

On the other hand, Souahlia et al. [11] conducted the experimental study of metal hydride container with concentric heat exchanger equipped with stainless steel fins. In this study, the effect of the variation of the operational parameters (such as flow mass and temperature of the cooling fluid, and applied pressure) on the sorption processes was studied. This study result shows that lowering the cooling temperature helped the hydride bed to cool more 
effectively so that the kinetics of the exothermic absorption reaction was accelerated. It was also found that by increasing the initial pressure at constant reference volume $\left(7600 \mathrm{~cm}^{3}\right)$, the absorption kinetic and the mass of absorbed hydrogen were improved due to the driving force for mass transfer increment. The driving force for mass transfer increment was affected by the initial pressure increment since the equilibrium pressure in this study was set by the initial experimental conditions.

Moreover, Gopal and Murthy [7] also investigated the effect of heat transfer fluid temperature by simulating a 1-D model of annular cylindrical metal hydride beds. The results confirmed that a large temperature difference between the tube wall and the hydride beds led to high heat and mass transfer rate. It was meant that the temperature of heat transfer fluid that effect of the tube wall temperature had a significant effect to the heat and mass transfer rate of the metal hydride beds. In conclusion, all of the studies that have been done in this field proved that heat transfer temperatures and reactor inlet/exit pressure are the MHR operating conditions that can be significantly affected its performance.

\section{RESEARCHES ABOUT THE EFFECTS OF THERMAL}

A number of studies have developed methods to increase heat transfer rate either by (i) improving the effective thermal conductivity of the metal hydride materials by methods such as adding conductivity-enhancing materials like aluminum or nickel foam $[8,12]$, integrating a copper wire net structure [13], mixing metal hydride powder with expanded graphite [14], or introducing internal plate-fin type heat exchanger [15] and/or (ii) incorporating active cooling systems such as circulating coolant inside the tank, or external fins [16]. The combination of enhancing conductivity and efficient cooling methods usually gives better performance [17]. This paper will discuss about adding aluminum foam to enhance heat transfer in the metal hydride tank.

Laurencelle and Goyette [8] performed 1-D of metal hydride reactor containing an aluminum foam with sphere shape. This simulation showed that the charging and discharging time of an MHR can be reduced by adding an aluminum foam on it. This study also found that the diameter of the reactor which is added an aluminum foam of $9 \%$ volume fraction can be increased by a factor of 7.5 while maintaining its performance as the reactor without metal foam.

Similar study also has been performed by Wang et al. [9] by using FLUENT software. This study performed a simulation of MHR containing metal foam which be cooled in two types cooling regimes, namely natural convection and active cooling. The result of this study showed that the aluminum foam improved the effective thermal conductivity but decreased the mass of hydrogen stored for high percentage of aluminum foam. It was also found that active cooling has a better filling rate than the natural convection. Moreover, Mellouli et al. [10] also studied the effect of the presence of metal foam in the MHR by extended the 2-D model of Jemni et al. [18]. This study observed the effect of the thermophysical properties, pore density, and pore size of a metal foam to the charging time of the MHR containing metal foam. 


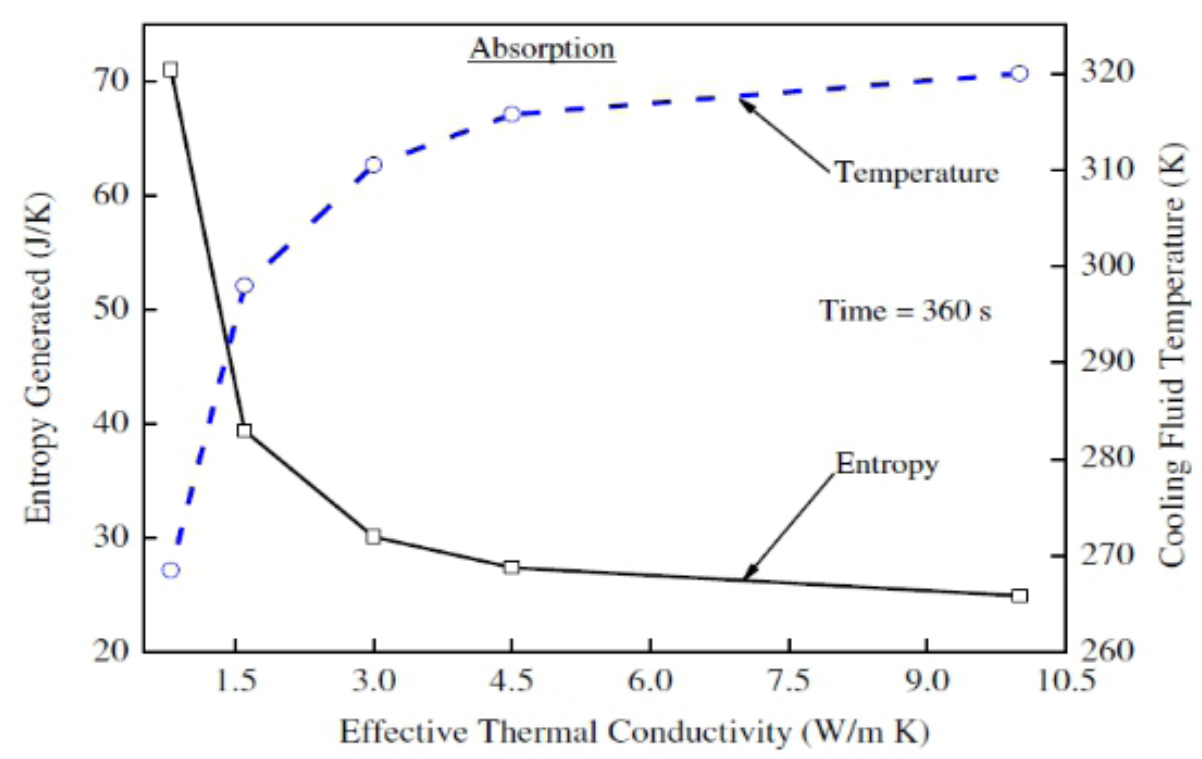

(a)

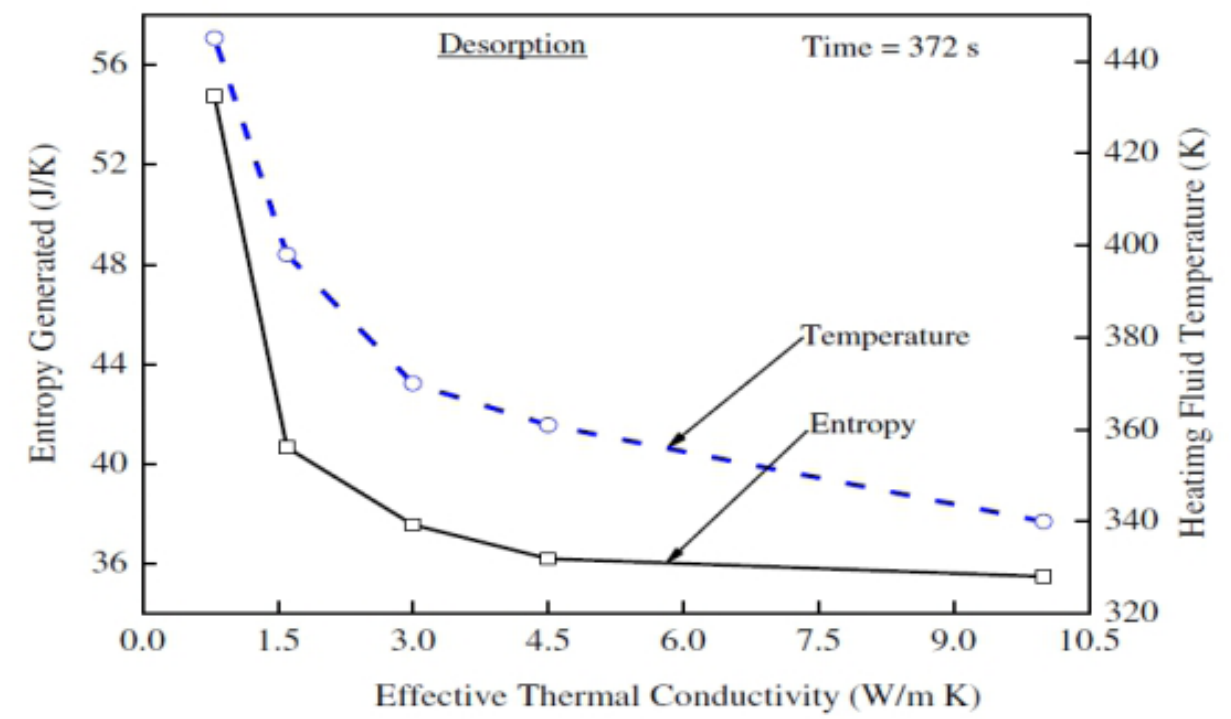

(b)

Figure 1.6 Effect of effective thermal conductivity on entropy generated and required cooling fluid temperature during (a) absorption and (b) desorption [19].

On the other hand, Patil and Gopal [19] studied the entropy generation and its relation to heating and cooling requirements of a metal hydride hydrogen storage system. In this study, a transient two dimensional energy equation along with suitable reaction kinetics and entropy balance equation was solved numerically. The amount of hydrogen transferred and the time in which the transfer toke place were kept fixed for a fixed mass of metal hydride in the reactor. The effects of several parameters on to the performance of the reactor have been investigated in this study. One of these parameters was the effective thermal conductivity of hydride bed.

Figures 1.6 (a) and (b) show some results of this study for the effect of effective thermal conductivity on entropy generated and required cooling fluid temperature during absorption and desorption respectively. It is seen that the variation of entropy generated was very high due to the high variation of the external fluid temperature, i.e. until $50 \mathrm{~K}$ for absorption and $100 \mathrm{~K}$ as the effective thermal conductivity value varied by about $10 \mathrm{~W} / \mathrm{mK}$. These figures 
also show that the effective thermal conductivity affected the performance significantly up to an "optimum" value, beyond which its effect was somewhat marginal. This fact indicated that there was a possibility of optimizing the effective thermal conductivity which usually conducted by adding some high thermal conductivity material (e.g. metal foam, expanded natural graphite) into the bed. However, the addition of high thermal conductivity material would affected the effective heat capacity of the bed and the permeability. Hence, it was essential to optimize the effective thermal conductivity of the bed for a given bed thickness by conceding the entropy generation in practice.

In conclusion, all of previous researches indicate that by adding metal foam into MHR would improve the MHR performance. However, the capacity of MHR must be sacrificed. The optimum metal foam volume fraction must be found so the improvement of MHR's performance doesn't affect the capacity of MHR poorly.

\section{CONCLUSION}

In conclusion, all of the studies that have been done in this field proved that heat transfer temperatures and reactor inlet/exit pressure are the MHR operating conditions that can be significantly affected its performance. So for the development of hydrogen storage the improvement must be focused on these operating conditions. Moreover, a number of studies have developed methods to increase heat transfer rate either by improving the effective thermal conductivity of the metal hydride materials or incorporating active cooling systems such as circulating coolant inside the tank, or external fins. The combination of enhancing conductivity and efficient cooling methods usually gives better performance. Thus, for improvement of the thermal management must be focused on the best material to improve thermal conductivity of metal hydride and the best efficient cooling methods without sacrified to much space in hydrogen storage.

\section{REFERENCES}

[1] H.B. Maad, F. Askri, and S.B. Nasrallah, Numerical investigation of heat and mass transfer during the desorption process of an $\mathrm{Mg}_{2} \mathrm{Ni}_{-} \mathrm{H}_{2}$ reactor. International Journal of Hydrogen Energy, vol. 38, pp. 4597-4610, 2013.

[2] R.B. Gupta, Hydrogen fuel : production, transport and storage. Boca Raton, Taylor and Francis Group, 2009.

[3] T. Forde, E. Naess, and V.A. Yartys, Modelling and experimental results of heat transfer in a metal hydride store during hydrogen charge and discharge. International Journal of Hydrogen Energy, vol. 34, pp. 5121-5130, 2009.

[4] J. Zhang, T.S. Fisher, P.V. Ramachandran, J.P. Gore, and I. Mudawar, A review of heat transfer issues in hydrogen storage technologies. Journal of Heat Transfer, vol. 127, pp. 1391-1399, 2005.

[5] L. Schalapbach and A. Zuttel, Hydrogen-storage materials for mobile applications. Nature, vol. 414, pp. 353-358, 2001.

[6] K. Jiao, X. Li, Yan Yin, Y. Zhou, S. Yu, and Qing Du, Effects of various operating condition on the hydrogen absorption processes in a metal hydride tank. Applied Energy, vol. 94, pp. 257-269, 2012 
[7] M.R. Gopal and S.S. Murthy, Prediction of heat and mass transfer in annular cylindrical metal hydride beds. International Journal of Hydrogen Energy, vol. 17, pp. 795-805, 1992

[8] F. Laurencelle and J. Goyette, Simulation of heat transfer in a metal hydride reactor with aluminium foam. International Journal of Hydrogen Energy, vol. 32, pp. 29572964, 2007.

[9] H. Wang, J.K. Prasad, and S.G. Advani, Hydrogen storage systems based on hydride materials with enhanced thermal conductivity. International Journal of Hydrogen Energy, vol. 37, pp. 290-298, 2012.

[10] S. Mellouli, H. Dhaou, F. Askri, A. Jemni, and S. B. Nasrallah, Hydrogen storage in metal hydride tanks equipped with metal foam heat exchanger. International Journal of Hydrogen Energy, vol. 34, pp. 9343-9401, 2009.

[11] A. Souahlia, H. Dhaou, F. Askri, S. Mellouli, A. Jemni, and S.B. Nasrallah, Experimental study and characterization of metal hydride containers. International Journal of Hydrogen Energy, vol. 36, pp. 4952-4957, 2011.

[12] Y. Chen, C.A.C. Sequeira, C. Chen, X. Wang, and Q. Wang, Metal hydride beds and hydrogen supply tanks as minitype PEMFC hydrogen sources. International Journal of Hydrogen Energy, vol. 28, pp. 329-333, 2003.

[13] M. Nagel, Y. Komazaki, and S. Suda, Effective thermal conductivity of a metal hydride bed augmented with a copper wire matrix. Journal of the Less Common Metals, vol. 20, pp. 35-43, 1986.

[14] H.P. Klein and M. Groll, Heat transfer characteristic of expanded graphite matrices in metal hydride beds. International Journal of Hydrogen Energy, vol. 29, pp. 1503-1511, 2004.

[15] T. Oi, K. Maki, and Y. Sakaki, Heat transfer characteristics of the metal hydride vessel based on the plate-fin type heat exchanger. Journal of Power Sources, vol. 125, pp. 5261, 2004.

[16] B.D. Macdonald and A.M. Rowe. Impacts of external heat transfer enhancements on metal hydride storage tanks. International Journal of Hydrogen Energy, vol. 31, pp. 1721-1731, 2006.

[17] F. Askri, M.B. Salah, A. Jemni, and S.B. Nasrallah, Optimization of hydrogen storage in metal-hydride tanks. International Journal of Hydrogen Energy, vol. 34, pp. 897-905, 2009.

[18] A. Jemni, S.B. Nasrallah, and J. Lamloumi, Experimental and theoretical study of a metal-hydrogen reactor. International Journal of Hydrogen Energy, vol. 24, pp. 631644, 1999.

[19] S.D. Patil and M.R. Gopal, Analysis of a metal hydride reactor for hydrogen storage. International Journal of Hydrogen Energy, vol. 38, pp. 942-951, 2013. 